\title{
Assessment of Blood Pressure in School Going Overweight Adolescents
}

\author{
Preeti Sharma ${ }^{1 *}$, Sunena Gupta ${ }^{1}$, Pradeep Kumar ${ }^{1}$, Rachna Sharma ${ }^{2}$, Tapan Mahapatra ${ }^{1}$ \\ ${ }^{1}$ Department of Biochemistry, Santosh Medical College and Hospital, Ghaziabad, India \\ ${ }^{2}$ Department of Biochemistry, TSM Medical College and Hospital, Lucknow, India
}

\begin{abstract}
*Address for Correspondence: Dr. Preeti Sharma, Associate Professor, Department of Biochemistry, Santosh Medical College and Hospital, Ghaziabad, India

E-mail: prcdri2003@yahoo.co.in
\end{abstract}

Received: 27 Jul 2018/ Revised: 25 Nov 2018/ Accepted: 18 Feb 2019

\begin{abstract}
Background: According to the various studies done previously, hypertension may starts since adolescence. Therefore early detection is always good to check its progression.

Methods: A case-control observational study based on school-going adolescents of both sexes between the age group of 10 to 16 years was done among 30 control and 30 overweight children. Their blood pressure, pulse pressure and anthropometric measurement were done according to the standard protocols. Unpaired student t-test was applied to compare the various parameters.

Results: We were found that the significant difference between antropometric and blood parameters values of normal and control subjects with p-value 0.001 .

Conclusion: Outcome of our study suggested that most of the overweight students were hypertensive's and might be at a risk of getting obsessed and will prone to future risk of cardiac disorders.
\end{abstract}

Key-words: BMI measurement, Hypertensive adolescent, Obese adolescent, Overweight, Overweight adolescent

\section{INTRODUCTION}

Hypertension is a worldwide problem rising at alarming rate. Incidences of hypertension among children and adolescents are rapidly growing and have often been ignored by the family members and physicians. If left unchecked the condition remains in adulthood with worse manifestation. High blood pressure (hypertension) is an unfavorable health parameter which has disastrous impact on health. Blood pressure (BP) is the pressure created by circulating blood on blood vessels walls and it is expressed as systolic pressure over diastolic pressure, measured in millimeters of mercury $(\mathrm{mmHg})$, above the surrounding atmospheric pressure' ${ }^{[1]}$. Normal Adult's systolic blood pressure (SBP) was nearly 120 millimeters

\section{How to cite this article}

Sharma P, Gupta S, Kumar P, Sharma R, Mahapatra T. Assessment of Blood Pressure in School Going Overweight Adolescents. SSR Inst. Int. J. Life Sci., 2019; 5(2): 2211-2217.

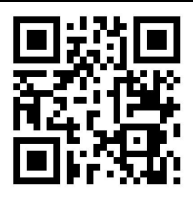

of mercury and diastolic was 80 millimeters of mercury [1]. Blood pressure is measured using an instrument known as mercury-tube sphygmomanometer ${ }^{[1]}$. In a number of cases obesity and overweight used to be the causative factors lie in the etiology of hypertension. Overweight is described by increased BMI while obesity is described by excessive body fat ${ }^{[2]}$. The growing obesity is a major source of unsustainable health, causes morbidity and mortality because of susceptibility of individual of getting hypertension, type 2 diabetes mellitus and few types of cancers and cardiovascular diseases ${ }^{[3]}$. Obesity affects seriously, many system of the body including cardiovascular system. Various Indicators for occurrence of hypertension are obesity, abdominal obesity and weight gain. The extra bulk of the body due to obesity requires sufficient supply of oxygen and nutrients in order to live, which requires the blood vessels to circulate more blood to obesity tissue site. This increases the workload of the heart as it pumps more blood through additional blood vessels. More circulating blood means more pressure on artery walls. Higher 
pressure on the arterial walls increases the blood pressure. Extra weight can raise heart rate and reduces body's ability to transport the blood through vessels ${ }^{[4]}$. A number of studies have been done in this global concern. A research done in the city Varanasi by Singh et al. ${ }^{[5]}$ as per census 2011, which is a community, based crosssectional study among 640 people aged between 25 to 64 years. According to Body Mass Index (BMI) values, study subjects either overweight or obese are more than one-third. With regard to abdominal obesity as measured by waist circumference, $40 \%$ subjects are at risk of developing hypertension. Men exhibited higher prevalence of hypertension and pre-hypertension than female. From the above background we therefore wish to assess the blood pressure in school going overweight adolescents by body mass index, waist-hip ratio, mean arterial pressure, pulse pressure.

\section{MATERIALS AND METHODS}

A case control observational study was conducted in 2017 for a period of 3 months from May to July, based on school-going adolescents of both sexes between age group of 10 to 16 years who were selected randomly. The study population was 60 students including 30 overweighed and 30 normals. Permission was obtained from the school principal and medical teacher to conduct the study. Informed consent was taken from every subject in the mother tongue (Hindi). Data collection was done by school visits with a pre-tested questionnaire. Before conducting the study, ethical clearance was taken from college ethical committee. Children suffering from any chronic cardiovascular, renal, musculocutaneous, endocrinal disease, obesity due to heredity, metabolic disorders, on any medicinal intake, were excluded from the study.

Blood pressure measurement- In this study, the blood pressure was regarded as systolic and diastolic pressure. Firstly the subjects were asked to rest for 5-10 minutes if they might engage in any physical activity then pressure was measured by sphygmomanometer. Systolic BP and Diastolic BP were measured by the auscultatory methods ${ }^{[6]}$. Pulse pressure was checked manually by using a normal wrist watch.

Anthropometric measurements- Weight was measured by weighing machine with a minimum amount of clothes wore. Measurement of height was done with stadiometer by making the subject standing straight.
Waist Circumference measurement was performed at the midpoint between the lower portion of the last rib and the upper edge of the iliac crest. It was done by elastic tape by having the subject in normal posture neither more inhaling nor exhaling. Hip Circumference measurement was done by elastic tape by having the subject in normal posture neither more inhaling nor exhaling ${ }^{[7]}$.

Weight status with respect to $\mathrm{BMI}$ as per WHO criteria ${ }^{[8]}$ is given in Table 1.

Table 1: Weight status in relation to BMI

\begin{tabular}{ccc}
\hline S. No. & BMI & Weight status \\
\hline $\mathbf{1}$ & Below 18.5 & Underweight \\
$\mathbf{2}$ & $18.5-24.9$ & Normal \\
$\mathbf{3}$ & $25-29.9$ & Overweight \\
$\mathbf{4}$ & $30-34.9$ & Obese Class I \\
$\mathbf{5}$ & $35.9-39.9$ & Obese Class II \\
$\mathbf{6}$ & 40 and above & Obese Class III \\
\hline
\end{tabular}

Statistical Analysis- An unpaired student's t-test was applied to analyze the case and control data using statistical software IBM SPSS version 23.0 (Chicago II, USA). A P-value $<0.05$ was considered statistically significant.

\section{RESULTS}

The study group consisted of 60 subjects including 30 overweighed and 30 normal male and female students, aged between 10 to 16 years. Their anthropometric characteristics and blood pressure were analyzed and compared. All the parameters including BMI, waist/hip ratio, systolic blood pressure, diastolic blood pressure, mean arterial blood pressure were significantly raised in study group as compared to control (with $p$ values 0.001). The comparative values of all aforesaid parameters are given in Table 2. From Fig. 1 \& Fig. 4 clearly shows, the differences of these parameters of normal and control group through graphical representation. 
Table 2: Comparison of anthropometric parameters and blood pressure of study subjects and control

\begin{tabular}{|c|c|c|c|c|c|}
\hline Variables & Group & $\mathbf{N}$ & Mean \pm SD & t-test value & $p$ value \\
\hline \multirow{3}{*}{ Body Mass Index } & Normal & 30 & $21.22 \pm 2.03$ & \multirow{3}{*}{13.19} & \multirow{3}{*}{$0.001 *$} \\
\hline & & & & & \\
\hline & Overweight & 30 & $27.18 \pm 1.40$ & & \\
\hline \multirow{3}{*}{ Waist/Hip Ratio } & Normal & 30 & $0.84 \pm 0.06$ & \multirow{3}{*}{3.53} & \multirow{3}{*}{$0.001 *$} \\
\hline & & & & & \\
\hline & Overweight & 30 & $0.89 \pm 0.04$ & & \\
\hline \multirow{3}{*}{ Systolic Blood Pressure } & Normal & 30 & $111.33 \pm 10.08$ & \multirow{3}{*}{15.43} & \multirow{3}{*}{$0.001^{*}$} \\
\hline & & & & & \\
\hline & Overweight & 30 & $147.33 \pm 7.84$ & & \\
\hline \multirow{3}{*}{ Diastolic Blood Pressure } & Normal & 30 & $70.50 \pm 6.06$ & \multirow{3}{*}{17.71} & \multirow{3}{*}{$0.001 *$} \\
\hline & & & & & \\
\hline & Overweight & 30 & $105.33 \pm 8.89$ & & \\
\hline \multirow{3}{*}{ Mean Arterial Pressure } & Normal & 30 & $84.09 \pm 6.47$ & \multirow{3}{*}{19.2} & \multirow{3}{*}{$0.001^{*}$} \\
\hline & & & & & \\
\hline & Overweight & 30 & $119.32 \pm 7.62$ & & \\
\hline \multirow{3}{*}{ Pulse Pressure } & Normal & 30 & $89.50 \pm 8.01$ & \multirow{3}{*}{5.92} & \multirow{3}{*}{$0.001^{*}$} \\
\hline & & & & & \\
\hline & Overweight & 30 & $100.60 \pm 6.40$ & & \\
\hline
\end{tabular}

Unpair t-test, *Significant

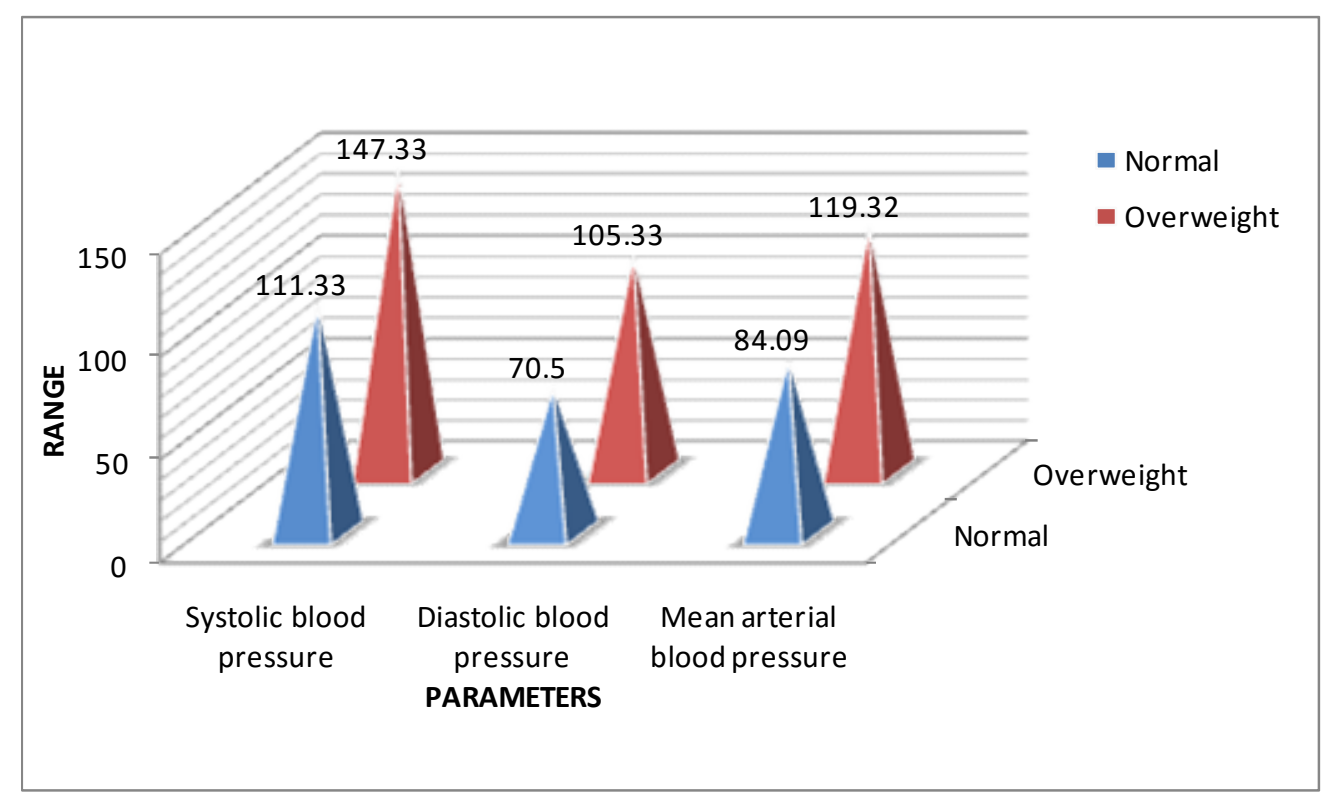

Fig. 1: Comparison of blood pressure and mean arterial blood pressure of normal and overweight children 


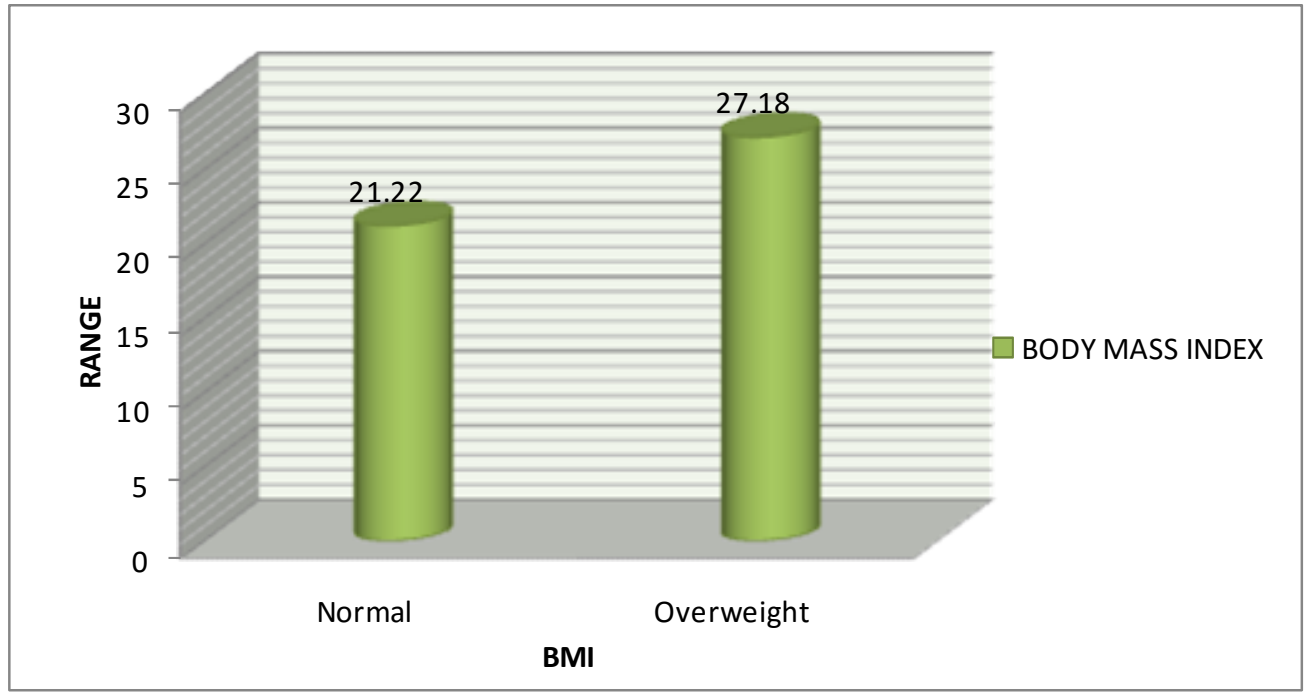

Fig. 2: BMI comparison of normal and overweight children

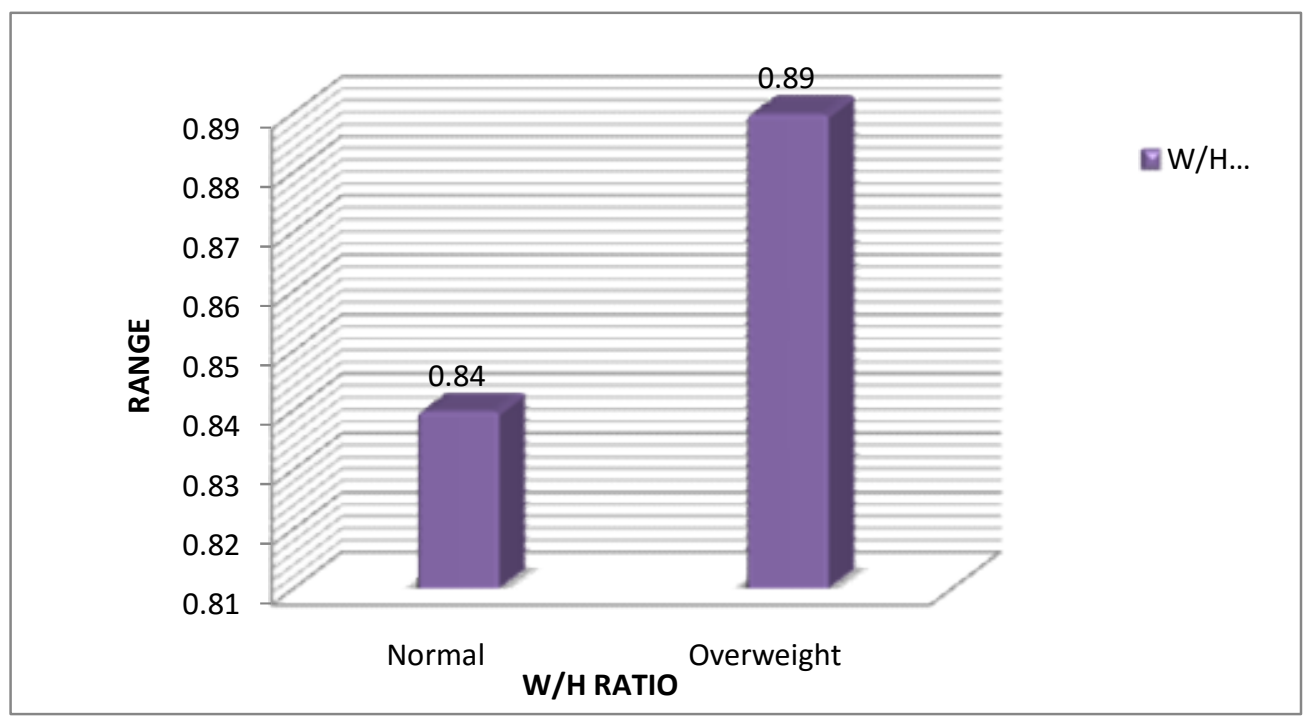

Fig. 3: Comparison of Waist/Hip ratio of normal and overweight children

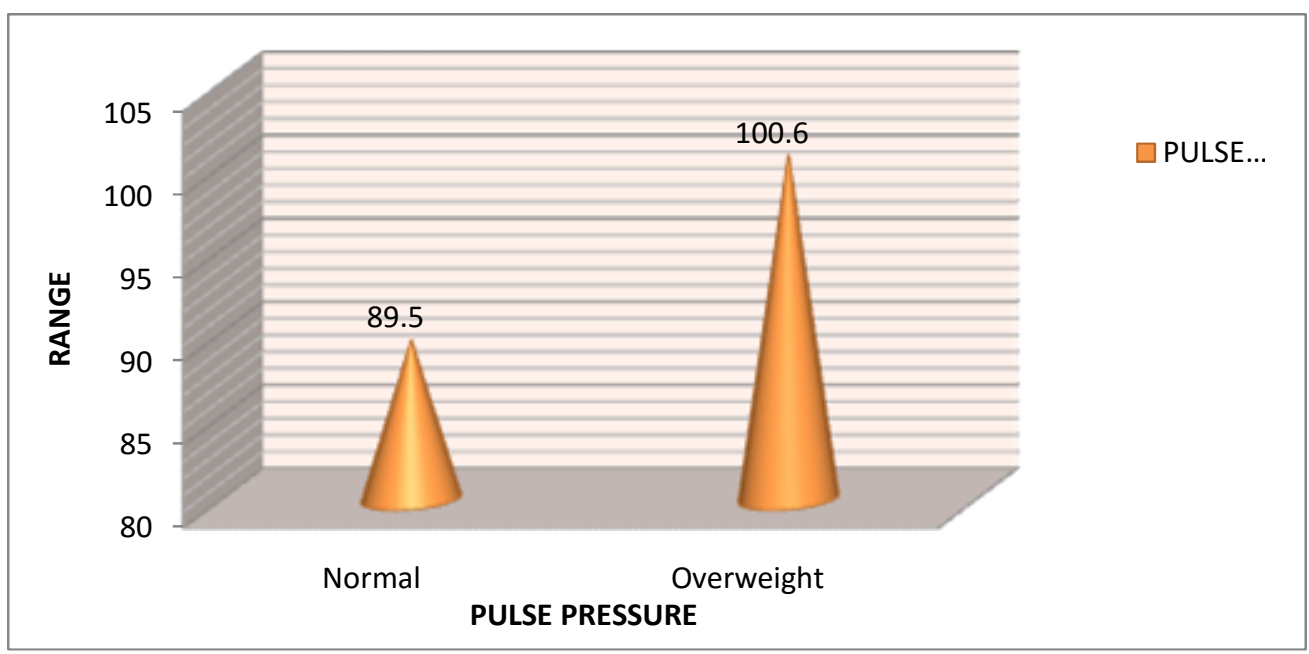

Fig. 4: Comparison of pulse pressure of normal and overweight children 


\section{DISCUSSION}

Hypertension is not a disease of sudden onset in adults but a gradual phenomenon which happens in a genetically susceptible individual due to the interaction of multiple causative factors over a period of time since a younger age. Primary prevention in hypertension starts from the school age group by searching high-risk individuals and initiating non-pharmaco-therapeutic interventions at the earliest and reducing the incidence of hypertension in the community. The present study showed the prevalence of high blood pressure among overweight school children. In our study, 10-16 years age group was involved. Overweight students had been found to have more mean arterial pressure and more waist/hip ratio as compared to control. Overweight adolescents mostly were not having a proper and regular sleep pattern, neither they used to eat nutritious food and nor doing regular and proper exercise to stay fit. In our study, we found a significant change in all the above said parameters i.e. $\mathrm{BMI}, \mathrm{W} / \mathrm{H}$ ratio, MAP, PP among study subjects as compared to control (with P-value 0.001). Results of the study were found compatible with various studies done earlier ${ }^{[8-11]}$ in this direction.

According to the literature survey the age, BMI, salt intake and family history of hypertension were key predictors of high blood pressure among the 10-16 years aged adolescents ${ }^{[12]}$. The higher calorie intake was documented among the hypertensive students [13]. Dietary management including reduced salt intake, low fat diet, intake of healthy food and increased fruit consumption are important primary preventions as well as in preventing the future incidence of hypertension in the susceptible school children.

A study was conducted in Lithuani by Dulskiene et al. ${ }^{[14]}$ from November 2010 to April 2012. This cross-sectional study included 7,638 subjects aged between 12 to 15 years old. Studies on pre-hypertension and hypertension among various age groups and different sample sizes of children and adolescents showed that the prevalence rates vary widely. They concluded the high prevalence of high blood pressure and overweight, obesity, and abdominal obesity were significantly associated with pre-hypertension and hypertension among Lithuanian school children. Another study was conducted in Jinan, China by Shu-Kang Wang et al. ${ }^{[15]}$ in the year 2011-2012. An obesity task force in China generated standard criteria for overweight and obese people based on Body
Mass Index (BMI) and Waist Circumference (WC) values appropriate for Chinese people ${ }^{[15]}$. A total of 1,870 people $(P=0.494)$ were examined under this cross-sectional study from the blocks randomly selected from among 6 communities of Jinan, China. They concluded that the relationship between hypertension and general obesity was stronger than the relationship between hypertension and either overweight or central obesity in both genders. One more study done in the year 2012 in Kasturba Medical College, Manipal University, Karnataka, was conducted by Rao et al. ${ }^{[16]}$ in which a cross-sectional community based survey among 1,239 people aged $\geq 30$ years was designed to estimate the prevalence and the sociodemographic correlates of hypertension. The study showed that a significant number of individuals were in pre-hypertension category. Among the study subjects, $16 \%$ had diabetes and a higher prevalence was noted among males as compared to females. Another study was done in the year 2016 at General Outpatient Clinic of the Federal Medical Centre, Owerri, Nigeria by Onuoha et al. ${ }^{[17]}$. They found positive correlation between central obesity and blood pressure. One more study done in Department of Community Medicine, Pt. Jawahar Lal Nehru Memorial Medical College, Raipur, Chhattisgarh, India by Panda et al. ${ }^{[18]}$ in the year 2017 and it was concluded that there is a rising burden of hypertension among study population and waist hip ratio was strongly associated with hypertension. From the various studies conducted in the direction ${ }^{[19-23]}$ results seem to be compatible with the outcome of our study, though smaller sample size and lake of gender wise data, have been the major limitations of our study.

\section{CONCLUSIONS}

The increasing trend of raised blood pressure among adolescents points towards a change in lifestyle that has been implicated in the causation of the increasing prevalence of hypertension. This trend calls for a modification of lifestyle from birth to adulthood. Adopting a healthy diet, lower salt intake, and partaking in physical activity would help to maintain normal BP values in both children and adolescents.

In our study, the systolic and diastolic blood pressures are strongly associated with BMI. Avoidance of fast food intake, increase in routine physical activity like vigorous walking, dancing, swimming shall prove to be panacea to check the future risk of developing hypertension and 
thereby preventing the individual from any risk of cardiac diseases. In future, however many large size studies with separate assessment of male and female variations are needed to be done in order to more clear the concept.

\section{ACKNOWLEDGMENTS}

All the authors thankfully acknowledge the support of Santosh Group of the institution, India for supporting the study.

\section{CONTRIBUTION OF AUTHORS}

Research concept- Dr. Preeti Sharma

Research design- Dr. Preeti Sharma

Supervision- Dr. Preeti Sharma and Dr. Pradeep Kumar

Materials- Ms. Sunena

Data collection-Ms. Sunena

Data analysis and interpretation- Ms. Sunena Dr. Pradeep Kumar

Literature search- Dr. Pradeep Kumar

Writing article- Ms. Sunena

Critical review- Dr. Rachna Sharma

Article editing- Dr. Tapan Mahapatra

Final approval- Dr. Preeti Sharma

\section{REFERENCES}

[1] Lobstein T, James WP, Cole TJ. Increasing levels of excess weight among chidren in England. Int. J. Obes. Relat. Metab. Disord., 2003; 27: 1136-1138.

[2] Kapil U, Singh P, Pathak P, Dwiedi N, Bhasin S. Prevalence of obesity among affluent adolescent school children in Delhi. Indian Pediatr., 2001; 39: 49-52.

[3] Gbenga O, Thomas P. Principles and techniques of blood pressure measurement. Cardiol. Clin., 2010; 28(4): 571-86.

[4] Nelson MJ, Ragland DR, Syme SL. Longitudinal prediction of adult blood pressure from juvenile blood pressure levels. Am. J. Epidemiol., 1992; 136(6): 633-45.

[5] Singh S, Shankar R, Singh GP. Prevalence and Associated Risk Factors of Hypertension: A Cross-Sectional Study in Urban Varanasi. Int. J. Hypertens., 2017, pp. 01-10.

[6] Babbs CF. Oscillometric measurement of systolic and diastolic blood pressures validated in a physiologic mathematical model. Biomed. Eng. Online, 2012; 11: 56.
[7] Gorstein J, Akre J. The use of anthropometry to assess nutritional status. World Health Stat. Q., 1988; 41(2): 48-58.

[8] Kulkarni P, Nagendra, Ashok NC, Kumar DS, Siddalingappa H, Madhu B. World Health Organization-Body Mass Index for Age Criteria as a Tool for Prediction of Childhood and Adolescent Morbidity: A Novel Approach in Southern Karnataka, India. Int. J. Prev. Med., 2014; 5(6): 695-702.

[9] Ogden CL, Carroll MD, Fryar CD, Flegal KM. Prevalence of obesity among adults and youth: United States, 2011-2014. NCHS Data Brief., 2015; 219: 01-08.

[10]Friedemann C, Heneghan C, Mahtani K, Thompson M, Perera R, Ward AM. Cardiovascular disease risk in healthy children and its association with body mass index: systematic review and meta-analysis. Br. Med. J., 2012; 345: e4759.

[11]Freedman DS, Mei Z, Srinivasan SR, Berenson GS, Dietz WH. Cardiovascular risk factors and excess adiposity among overweight children and adolescents: the Bogalusa Heart Study.J Pediatr., 2007; 150: 12-17.

[12]Hansen ML, Gunn PW, Kaelber DC. Underdiagnosis of hypertension in children and adolescents. JAMA, 2007; 298: 874-79.

[13]Sorof JM, Lai D, Turner J, Poffenbarger T, Portman RJ. Overweight, ethnicity, and the prevalence of hypertension in school-aged children. Pediatr., 2004; 113: $475-82$.

[14]Dulskiene V, Kuciene R, Medzioniene J, Benetis R. Association between obesity and high blood pressure among Lithunian adolescents: Cross sectional study. Italian J. Pediatr., 2014; 40: 102-06.

[15] Wang SK, Ma W, Wang S, Yi XR, Jia HY, Xue F. Obesity and Its Relationship with Hypertension among Adults 50 Years and Older in Jinan, China. PLoS ONE, 2014; 9(12): e114424.

[16]Rao CR, Kamath VG, Shetty A, Kamath A. High Blood Pressure Prevalence and Significant Correlates: A Quantitative Analysis from Coastal Karnataka, India 2013. Prev. Med., 2013; pp. 01-06.

[17] Onuoha FM, Ebirim CC, Ajonuma BC, Alabi NA, Eseigbe $\mathrm{P}$, Okezue OS. Correlation between central obesity and blood pressure in an adult Nigerian population. J. Insulin resistance, 2016; 1(1): 01-05. 
[18]Panda PS, Jain KK, Soni GP, Gupta SA, Dixit S, Kumar J. Prevalence of hypertension and its association with anthropometric parameters in adult population of Raipur city, Chhattisgarh, India. I. J. Res. Med. Sci., 2017; 5(5): 2120-25. doi: 10.18203/23206012.ijrms20171854.

[19]Irgil E, Erkenci Y, Ayetekin N, Ayetekin H. Prevalence of hypertension in School children aged 13-18 yrs in Gemlike, Turkey. Euro. J. Public Health, 1998; 40: 176-78. doi:
[20]Misra SK, Dutta K, Dua P, Ghosh C. Associations of Obesity $S$ Indices with Cardiorespiratory Fitness in Bengali School Going Boys in India. Int. J. Life. Sci. Scienti. Res., 2017; 3(1): 853-61.

[21]Parashar D, Sahu RK. A Methodological Analysis on Obesity. Int. J. Life. Sci. Scienti. Res., 2015; 1: 12-14.

[22] Ng'andu NH. Blood pressure levels of Zambian rural adolescents and their relationship to age, sex, weight, height and three weights for height indices. Int. J. Epidemiol., 1992; 21: 246-52.

[23]Raj M, Sundaram R, Paul M, Kumar K. Blood pressure distribution in children. Indian Pediatr., 2010; 47: 477-85. 